\title{
A novel approach for the production and purification of mannosylerythritol lipids (MEL) by Pseudozyma tsukubaensis using cassava wastewater as substrate
}

Article

Accepted Version

Creative Commons: Attribution-Noncommercial-No Derivative Works 4.0

De Andrade, C. J., De Andrade, L. M., Rocco, S. A., Sforça, M. L., Pastore, G. M. and Jauregi, P. (2017) A novel approach for the production and purification of mannosylerythritol lipids (MEL) by Pseudozyma tsukubaensis using cassava wastewater as substrate. Separation and Purification Technology, 180. pp. 157-167. ISSN 1383-5866 doi: https://doi.org/10.1016/j.seppur.2017.02.045 Available at https://centaur.reading.ac.uk/69827/

It is advisable to refer to the publisher's version if you intend to cite from the work. See Guidance on citing.

To link to this article DOI: http://dx.doi.org/10.1016/j.seppur.2017.02.045

Publisher: Elsevier

All outputs in CentAUR are protected by Intellectual Property Rights law, including copyright law. Copyright and IPR is retained by the creators or other copyright holders. Terms and conditions for use of this material are defined in the End User Agreement. 


\section{www.reading.ac.uk/centaur}

\section{CentAUR}

Central Archive at the University of Reading

Reading's research outputs online 


\section{A novel approach for the production and purification of mannosylerylthritol lipids}

(MEL) by Pseudozyma tsukubaensis using cassava wastewater as substrate *Cristiano José de Andrade ${ }^{12}$, Lidiane Maria de Andrade ${ }^{2}$, Silvana Aparecida Rocco ${ }^{3}$, Mauricio Luis Sforça ${ }^{3}$, Gláucia Maria Pastore ${ }^{1}$, Paula Jauregi ${ }^{4}$

*Corresponding author - eng.crisja@gmail.com, + 55 (19) 98154-3393, Present address: ${ }^{1}$ Department of Food Science, Faculty of Food Engineering, University of Campinas, P.O. Box 6121, 13083-862, Campinas, SP, Brazil; ${ }^{2}$ Chemical Engineering Department of Polytechnic School of the University of São Paulo, São Paulo, SP, Brazil, ${ }^{3}$ Brazilian Bioscience National Laboratory, Campinas, SP, Brazil, ${ }^{4}$ Department of Food and Nutritional Science, University of Reading, Reading-UK.

\footnotetext{
ABSTRACT

P. tsukubaensis is a yeast-like microorganism that synthesized the biosurfactant mannosylerythritol lipids-B (MEL-B). Production cost can be one of the drawbacks of biosurfactants production. Therefore the development of efficient and cost effective purification strategies and the use of by-products in the culture medium could serve as important strategies to reduce overall process cost. The aim of this work was to evaluate the production of MEL using cassava wastewater, a hydrophilic medium composed of a low-cost substrate which is a by-product of cassava processing, followed by foam fractionation and ultrafiltration of MEL . Cassava wastewater proved to be a feasible culture medium for $P$. tsukubaensis and MEL-B production as the yield (1.26 g L) was similar to that reported by others using water-soluble carbon sources (up to $2 \mathrm{~g} / \mathrm{L}$ ). Interestingly ultrafiltration with $100 \mathrm{KDa}$ MWCO memabranes (using $20 \mathrm{~mL}$ centrifugal devices) led to the purification of MEL-B in one step since $\approx 80 \%$ of MEL
} 
was recovered, while more than $95 \%$ of proteins were found in the permeate. The scale up of the ultrafiltration (up to $500 \mathrm{~mL}$ ) using a cross flow filtration unit led to very similar results. Overall the ultrafiltration led to a threefold increase in MEL purity in terms of protein (at both scales). The chemical characterisation by NMR confirmed the production of MEL-B homologue and also the production of a second stereoisomer $\approx$ 9\%, while the CG-MS and MALDI-TOFMS analysis confirmed the main fatty acids within the structure of MEL-B ( C8:0 and 12:0 and C8:0 and C14:1) . Therefore, the

process developed here was found to be a good alterntative to the conventional production of MEL which uses synthetic culture medium, solvent extraction (ethyl acetate) and column chromatography (silica) for its purification.

Keywords: Pseudozyma tsukubaensis; cassava wastewater; mannosylerythritol lipids-B; ultrafiltration

\section{Introduction}

Biosurfactants are compounds produced by living cells, for instance, microorganisms, vegetables, animal cells, among others. Their chemical structure consists in two parts, a polar (hydrophilic) moiety and non-polar one (hydrophobic).

Rhamnolipids, surfactin, sophorolipids are the most well-known biosurfactants, however, others biosurfactants such as mannosylerythritol lipids (MEL) have been receiving more and more attention. MEL have a remarkable chemical structure (Fig. 1). 


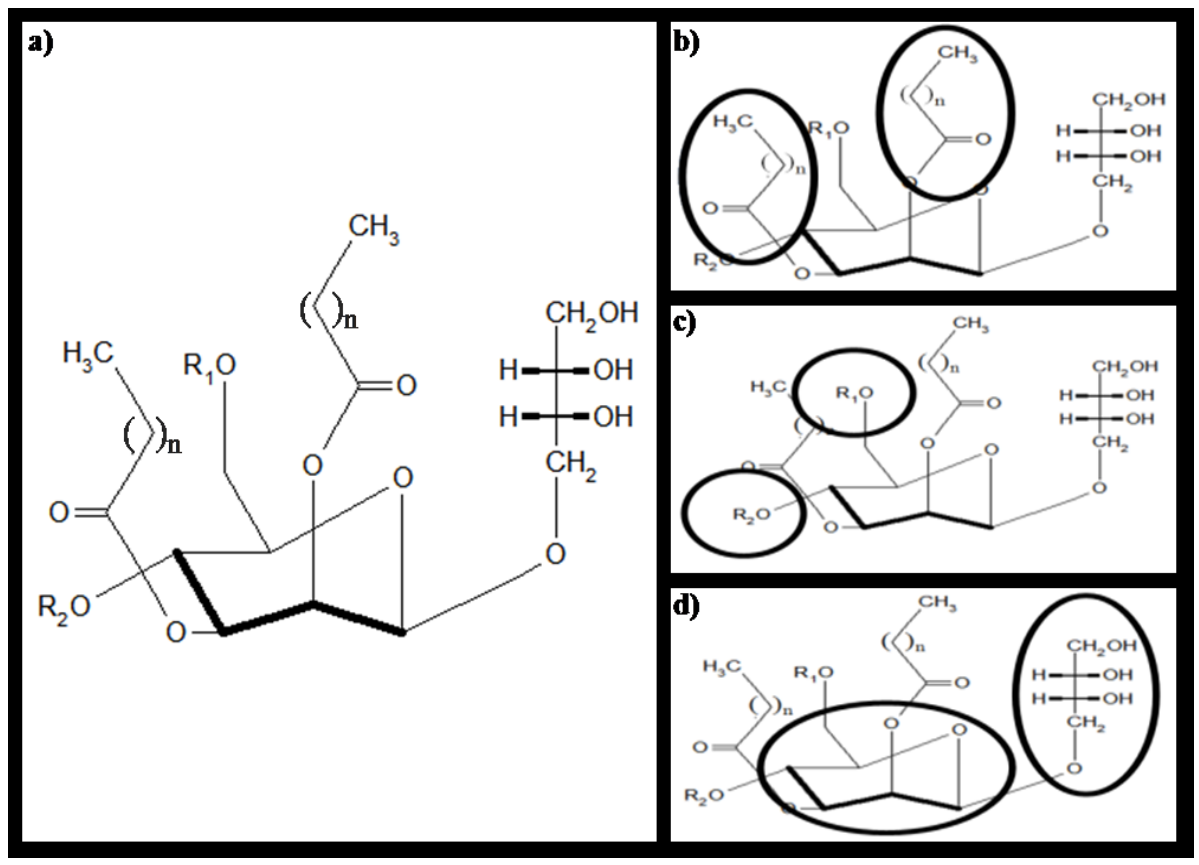

Figure 1. Structure of MEL; a) general structure, b) fatty acids, c) acetylation of C4'and/or C-6' in mannose, d) mannose and erythritol; $n=8$ to 14 . Adapted from Arutchelvi et al. (2008),

MEL consist of a mixture of partially acylated derivatives of $4-O-\beta-\mathrm{D}^{-}$ mannopyranosyl-D-erythritol (Figures 1-2) (Morita et al. 2015a, Yu et al. 2015, Faria et al. 2014, Fan et al. 2014, Sajna et al. 2013, Arutchelvi et al. 2008, Hubert et al. 2012, Konishi et al. 2011, Fukuoka et al. 2008, 2011, 2012). In this sense, there are 4 MEL homologues $-\mathrm{A},-\mathrm{B},-\mathrm{C}$ and $-\mathrm{D}$, which are classified exclusively based on the acetylation of C-4'and C-6' (mannose) (Fig. 2) (Arutchelvi et al. 2008, Hubert et al. 2012, Konishi et al. 2011, Fukuoka et al. 2008, 2011, 2012, Marchant and Banat, 2012). 


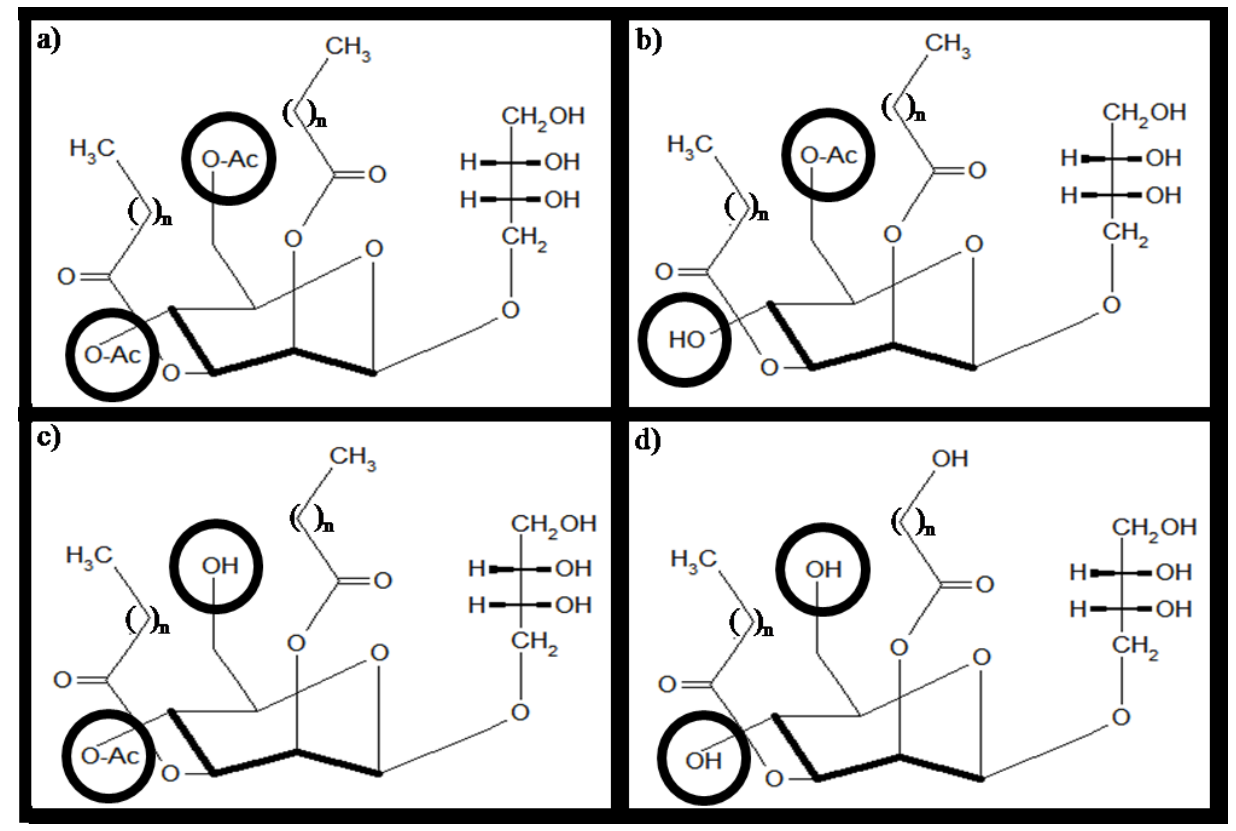

Figure 2. MEL homologues $-\mathrm{R}_{1}$ and $\mathrm{R}_{2}$ groups are highlighted in bold circles; a) MELA $\left(\mathrm{R}_{1}=\mathrm{R}_{2}=\right.$ acetyl group $\left.), \mathrm{b}\right)$ MEL-B $\left(\mathrm{R}_{1}=\right.$ acetyl group, $\mathrm{R}_{2}=\mathrm{H}$, c) MEL-C $\left(\mathrm{R}_{1}=\mathrm{H}\right.$, $\mathrm{R}_{2}=$ acetyl group), and d) MEL-D $\left(\mathrm{R}_{1}=\mathrm{R}_{2}=\mathrm{H}\right)$.

There is an increasing interest in MEL due to their potential application such as pharmaceutical (Hubert et al. 2012) including schizophrenia (Yu et al. 2015, Sajna et al. 2013), biodegradation of petroleum, cosmetic industry (Recke et al. 2013), antitumor against human leukaemia and mouse melanoma cells, ligand for immunoglobulin purification (Faria et al. 2014, Sajna et al. 2013, Yu et al. 2015), or as proved by Sajna et al. (2013) that crude biosurfactant - MEL-C - can be used in laundry detergent formulations.

MEL are synthesized by several microorganisms such as Schizonella melanogramma, Candida sp. (currently known as Pseudozyma sp.) as a major component, whereas Ustilago sp. produces them as a minor component. MEL are also, produced by Kurtzmanomyces sp. (Arutchelvi et al. 2008, Morita et al. 2015a). In this 
sense, $P$. tsukubaensis has been receiving special attention, since $P$. tsukubaensis synthesizes only MEL-B contrary to other Pseudozyma species that produce a mixture of different MEL homologues (Fukuoka et al. 2008, Konishi et al. 2011).

The production of MEL in flask fermentation is relatively well-reported, whereas a few attempts have been made to produce MEL at bioreactor scale (Arutchelvi et al. 2008). In addition, MEL are mostly produced using hydrophobic carbon sources (e.g soybean oil). Thus, the production of MEL using water-soluble carbohydrates has not been investigated much (Morita 2009a, Morita et al. 2015a). The use of watersoluble carbohydrates is advantageous since it will facilitate the purification process. Moreover the production of MEL using a waste product as substrate such as, cassava wastewater has not been much investigated (Fai et al. 2015).

Cassava wastewater is the main residue of cassava starch industry which corresponds to approximately $30 \%\left(\mathrm{w} \cdot \mathrm{w}^{-1}\right)$. This waste has high nutrients content $(74 \mathrm{~g}$ of total solids/L), that on fresh weight basis is composed of: protein $1 \%$, lipids $0.2 \%$, fermentable carbohydrates including glucose, fructose and saccharose $35 \%$, starch $30 \%$, fibers $1 \%$, nitrogen $0.22 \%$, phosphorus $0.03 \%$, calcium $0.4 \%$, sodium $0.002 \%$, niacin $0.0006 \%$, among others, which can be used in many biotechnological processes for example, to produce biosurfactants (Andrade, et al., 2016a-c).

Regarding biosurfactant production costs, the purification process is the most important step representing $60 \%$ of the total cost (Chen et al. 2008b; Saharan et al. 2012). In this context, Isa et al. (2007) and Chen et al. (2007) have developed an interesting strategy for the purification of the biosurfactant surfactin: a two-step ultrafiltration (UF) process that led to both high recovery and purity of surfactin. This method takes advantage of the self-aggregation property of (bio)surfactants when at 
concentrations higher than their critical micellar concentration (CMC); thus this is also applicable to MEL. To the best of our knowledge, the application of UF for purification of MEL has not been investigated yet. Purification of MEL is typically carried out by ethyl acetate extraction followed by open column chromatography (silica) (Morita et al. 2015, Faria et al. 2014, Fan et al. 2014, Sajna et al. 2013, Recke et al. 2013, Konishi et al. 2011, Hubert et al. 2012).

As highlighted by Hubert et al. (2012), much research has focused on reducing production costs of glycolipids that are synthesized by microorganisms. In the present work a novel bioprocess was developed which could result in a more cost effective process. The main novel aspects that were investigated were: (i) production of MEL at bench-top bioreactor using the most promising MEL (only MEL-B) producers- $P$. tsukubaensis, and a low-cost substrate - an agro-industrial waste (cassava wastewater) as culture medium, (ii) purification process based on UF (Fig. 3).

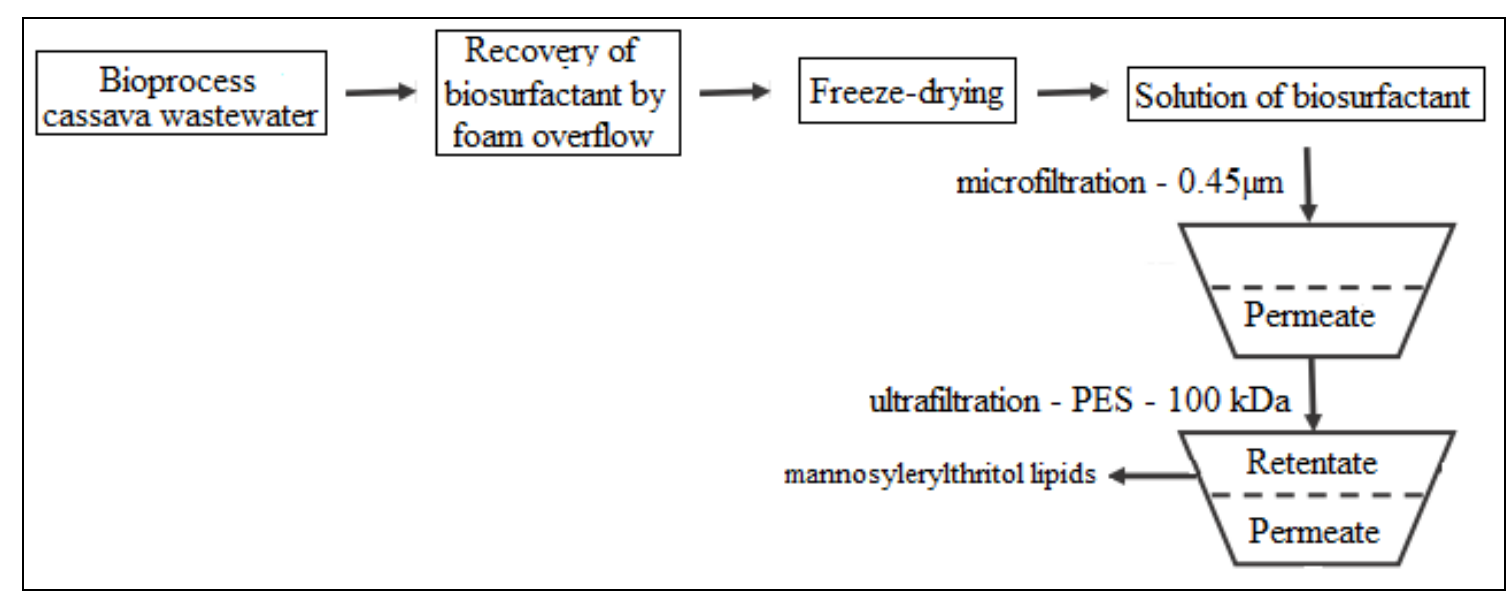

Figure 3. Overview of ultrafiltration of MEL produced from $P$. tsukubaensis using cassava wastewater as culture medium. 
This study was carried out as an international collaboration between Brazil and United Kingdom. Thus, it should be noted that the freeze-drying step was only added to facilitate the shipment of material. Therefore, at industrial production scale, the freezedrying step would be unnecessary since MEL (foam) would be directly taken to the ultrafiltration process.

\section{Material and methods}

\subsection{Chemicals}

The chemicals used: acetonitrile (Synth $\approx 99.8 \%$ ), bicinchoninic acid kit (SigmaAldrich), bovine serum albumin (Sigma-Aldrich $\geq 98 \%$ ), chloroform (Synth $\approx 99.8 \%$ ), deuterated chloroform (Sigma-Aldrich $>99.8 \%$ ), methanol (Sigma-Aldrich $\geq 99.6 \%$ ), tetramethylsilane (Sigma-Aldrich $>99 \%$ ), trifluoroacetic acid (Sigma-Aldrich $\geq 99 \%$ ), trypan blue $0.4 \%$ (Thermo Fisher), $\alpha$-cyano-4-hydroxycinnamic acid (Sigma-Aldrich $\geq$ $98 \%$ ), acetonitrile (Merck $\approx 99.9 \%)$.

\subsection{Production of mannosylerylthritol lipids (MEL)}

\subsubsection{Microorganism and inoculum}

A loop of $P$. tsukubaensis culture growth pertaining to the culture collection of the BioFlavors Laboratory of DCA/FEA/UNICAMP was transferred to medium composed by 10 g.L -1 $^{-1}$ saccharose, 10 g.L -1 $^{-1}$ glucose, 20 g.L. ${ }^{-1}$ peptone, 10 g.L L $^{-1}$ yeast extract, 0.4 g.L $\mathrm{L}^{-1} \mathrm{MgSO}_{4}$ and 5 g.L $\mathrm{L}^{-1} \mathrm{~K}_{2} \mathrm{HPO}_{4}$ (YEPD) and maintained in incubator (48 h, $\left.30{ }^{\circ} \mathrm{C}\right)$. It was mixed with sterilized glycerol 90 and $10 \%\left(\mathrm{v} \cdot \mathrm{v}^{-1}\right)$ respectively, placed in microtubes $(1 \mathrm{~mL})$ and stored $\left(-18^{\circ} \mathrm{C}\right)$. Then, one microtubes was placed in a conical flask containing supplemented yeast extract peptone glucose broth (YEPD) and 
maintained at $30{ }^{\circ} \mathrm{C}$ for $48 \mathrm{~h}$ in a rotary shaker incubator at a speed of $150 \mathrm{rpm}$. The medium was standardized at 0.5 by measuring the optical density at $\lambda=600 \mathrm{~nm}$ for a viable cell (which according with calibration curve represents in wet weight basis, $0.02155 \mathrm{~g}$ of cells per $100 \mathrm{~mL}$ of YEPD) and a volume $7 \%\left(\mathrm{v} \cdot \mathrm{v}^{-1}\right)$ used as inoculum.

\subsubsection{Culture medium}

Cassava wastewater (variety IAC-13) was collected from a flour industry and transported to laboratory at room temperature. After that, the residue was boiled, centrifuged at 10,000 g during 10 minutes and $5{ }^{\circ} \mathrm{C}$ (Beckman Coulter, AlegraX-22r). The supernatant was stored $\left(-18^{\circ} \mathrm{C}\right)$ and unfrozen before the bioprocess (Andrade et al., 2016a-b).

\subsubsection{Bioprocess parameters and sampling}

Culture medium, cassava wastewater, was sterilized at $121{ }^{\circ} \mathrm{C}$ for 20 minutes. Then it was added to the bioreactor - Bioflo® \& Celligen ${ }^{\circledR} 310$ - New Brunswick Scientific (3.0 liters working volume). The conditions were $100 \mathrm{rpm}$ and aeration rate of $0.4 \mathrm{vvm}$ ( 1 vessel volume per minute) were kept in the firsts $24 \mathrm{~h}$ then $150 \mathrm{rpm}$ and 0.8 vvm from 24 to $84 \mathrm{~h}$, for all 7 bioprocess (F-1...F-7). Samples were collected in each 12 hour-basis until 84 h (bioreactor). Viable cell count, content of glucose, volume of foam, surface tension measurements (ST) used parameters. 


\subsubsection{Analytical methods of production}

\subsubsection{Cell growth}

A volume of $1 \mathrm{~mL}$ of each sample (culture medium) was dyed (one drop) with trypan blue $(0.2 \%)$ and cells were counted under a microscope by Neubauer chamber. when the concentration was higher than $2 \times 10^{6}$ cells per $\mathrm{mL}$ serial dilution $(\mathrm{NaCl} 0.7 \%)$ was used.

\subsubsection{Content of glucose}

Content of glucose was analyzed by enzymatic/colorimetric technique (Laborlab).

\subsubsection{Measurements of surface activity}

Approximately $20 \mathrm{~mL}$ of each sample, culture medium and centrifuged foam, were centrifuged at $10^{4} \mathrm{~g}$ for 20 minutes. The ST of the supernatant of these samples and their dilutions (CMDs) was measured using the plate method in a Krüss GmbH K12 tensiometer (Hamburg, Germany) (Andrade et al., 2016a-b). Critical micelle dilutions (CMDs) are the ST values of the samples diluted 10-times (CMD-1), 100times (CMD-2) and 1000-times (CMD-3).

\subsubsection{MEL recovery}

Foam from the bioreactor was collected during its production at the top of the bioreactor (Andrade et al., 2016a-b). At the end of bioprocess the volume of the collapsed foam (liquefied), was measured and centrifuged at $10^{4} \mathrm{~g}$ for 20 minutes. Then, the ST and its CMDs measured using the supernatant phase - plate method (Andrade et 
al., 2016a-b). Finally, the collapsed foam was lyophilized (LS 3000 TERRONI) and stored at $-18{ }^{\circ} \mathrm{C}$. Samples collected every12-hours from the foam of the first bioprocess (F-1) were freeze dried and stored.

\subsection{Purification of MEL by ultrafiltration process}

\subsubsection{Process overview}

Samples of foam powder (lyophilized) - bioprocesses F-1 (12-hour basis), F-2, F-3 and F-4 - were solubilized in buffer 8.5, filtered $0.45 \mu \mathrm{m}$ and used to determine the MEL concentration by High Performance Liquid Chromatography (HPLC). A volume of F-2 (15 mL) was placed in the centrifugal device polyethersulfone (PES) $100 \mathrm{kDa}$ (Vivaspin) and centrifuged. The retentate $(0.8 \mathrm{~mL})$ was diluted with $14.2 \mathrm{~mL}$ of buffer (Isa et al. 2008). The concentration of protein, MEL concentration and nanoparticle size were measured.in the feed, retentate and permeate,

Finally, the scale up was carried out with a volume of $250 \mathrm{~mL}$. The concentration of protein, MEL concentration and nanoparticle size, also the flow rate of UF were determined for the feed and permeate.

\subsubsection{Analytical methods of purification}

\subsubsection{Determination of MEL concentration}

MEL concentration was determined by reverse phase HPLC. The system used was a Gilson 306 (Rockford, IL, USA), with a C-18 column of dimensions $250 \mathrm{~mm} \times$ $4.6 \mathrm{~mm}$ and a particle size of $5 \mu \mathrm{m}$. The flow rate of the mobile phase was $1.0 \mathrm{~mL} \cdot \mathrm{min}^{-1}$ - isocratic chromatography - with $70 \%$ acetonitrile in $0.1 \%$ trifluoroacetic acid and $30 \%$ HPLC-grade water in $0.1 \%$ trifluoroacetic acid. A $50 \mu \mathrm{L}$ sample was injected in each 
run which lasted for 65 minutes (55 minutes with detector on and 10 minutes as column cleaning step). The eluent absorbance was monitored at $206 \mathrm{~nm}$. The system was calibrated using MEL-B standard obtained from Toyobo-Japan. The area of the peaks eluting between 11, 16, 23 and 25 minutes, which were the same as those of the standard, were added to obtain the total MEL peak area. This value was used to determine the MEL concentration in the samples.

\subsubsection{Kinetics of MEL production}

Samples of lyophilized foam, which were taken at $12 \mathrm{~h}$ basis (only for the F-1) were solubilized $\left(\approx 700 \mathrm{mg} . \mathrm{L}^{-1}\right)$ in tris buffer $10 \mathrm{mM} \mathrm{pH} 8.5$ and analyzed by HPLC.

\subsubsection{Protein concentration}

The total amount of protein at different purification stages was determined by the bicinchoninic acid method (BCA). A calibration curve was produced using bovine serum albumin (BSA) as the protein standard solution (Isa et al. 2007).

\subsubsection{Micelle size of MEL and its relation with the concentration}

The nanoparticle size of all samples of ultrafiltration process was analyzed by dynamic light scattering (DLS), using a Zetasizer Nano ZS system (Malvern, UK). This system is able to detect particles ranging from $0.6 \mathrm{~nm}$ to $6 \mu \mathrm{m}$ (Isa et al. 2007). 


\subsubsection{Centrifugal device of ultrafiltration}

The separation was repeated twice using two brand new Vivaspin 20 (Sartoriuos) with PES - $100 \mathrm{kDa}$, containing membrane of $6 \mathrm{~cm}^{2}$ of active area. Samples of lyophilized foam of F-2 (please see item 2.2.3) were diluted in tris buffer 10 $\mathrm{mM} \mathrm{pH} 8.5$ at 1836.32 and $1407.75 \mathrm{mg} . \mathrm{L}^{-1}$ of foam (powder). Then, $15 \mathrm{~mL}$ (feed) were placed in the ultrafiltration unit $(100 \mathrm{kDa})$, centrifuged at $2205 \mathrm{~g}, 10$ minutes and $20{ }^{\circ} \mathrm{C}$. Finally, all solutions (retentates and permeates of UF) were analyzed for concentration of MEL, particle (micelle) size and concentration of protein.

The rejection of MEL or protein by a membrane was determined as the rejection coefficient $(\mathrm{R})$ which was defined as:

Equation $1 . R=\left[\left(\mathrm{C}_{\mathrm{F}}-\mathrm{C}_{\mathrm{P}}\right) / \mathrm{C}_{\mathrm{F}}\right]$

where $C_{F}$ and $C_{P}$ are the concentration of MEL or protein in the feed $\left(C_{F}\right)$ and permeate $\left(\mathrm{C}_{\mathrm{P}}\right)$, respectively.

The purity was also calculated in terms of protein as mass fraction of MEL in relation to sum of mass of MEL and protein $(\mathrm{Pp})$ as shown below:

Equation 2. $\mathrm{P}_{\mathrm{P}}=\left[\left(\mathrm{C}_{\mathrm{M}} / \mathrm{C}_{\mathrm{M}}+\mathrm{C}_{\mathrm{P}}\right)^{*} 100\right]$

where $C_{M}$ and $C_{P}$ are the concentration of MEL and concentration of protein, respectively. 
Equation (2) was applied to calculate the purity in the feed, retentate and permeate.

\subsubsection{Top-bench ultrafiltration - scale up}

Lab scale UF of the fermentation broth was performed with a magnetically stirred Labscale TFF system (Millipore) with PES $100 \mathrm{kDa}$ (Pellicon® XL) of an effective filtration area of $50 \mathrm{~cm}^{2}$. The stirrer speed and pump speed were kept at 3.0 and 2.5, respectively. The feed pressure gauge and retentate pressure gauge were kept at between 10-30 psi and 10 psi, respectively.

The system was cleaned before and after the experiments and stored at $4{ }^{\circ} \mathrm{C}$, according to the manufacture's protocol.

The UF was carried out twice with $250 \mathrm{~mL}$ of feed, MEL solution 1091.59 mg. $\mathrm{L}^{-1}$ of foam (powder), that is, at $294.73 \mathrm{mg} . \mathrm{L}^{-1}$ of pure MEL (see MEL concentration analysis). The flow rate was monitored during the course of UF.

Equation $3=\left(\mathrm{LMH}\right.$ or L. $\left.\mathrm{m}^{-2} \cdot \mathrm{h}^{-1}\right)=\left[\right.$ flow rate $\left(\mathrm{mL} \cdot \mathrm{min}^{-1}\right) \cdot$ membrane area $\left.\left(\mathrm{cm}^{-2}\right)\right]$ x 600

After the reduction in the feed of $25 \mathrm{~mL}$, samples of permeate and feed were taken and the concentration of MEL (HPLC), nanoparticle size (DSLS) and proteins measured.

The rejection of MEL or protein was determined by applying Eq. 1 .

\subsection{Molecular identification of MEL}

\subsubsection{Infrared spectroscopy}


Infrared spectra were measured with an IRA-3 spectrophotometer (JASCO) (Kitamoto et al. 1990).

\subsubsection{Gas chromatography coupled to mass spectrometry (GC-MS)}

The fatty acids of the purified product were examined by gas chromatographymass spectrometry (GC-MS). The methyl ester derivatives of fatty acids were prepared by mixing the purified MEL-B $(10 \mathrm{mg})$ with $5 \% \mathrm{HCl}-\mathrm{MeOH}$ reagent $(1 \mathrm{~mL})$ at $80{ }^{\circ} \mathrm{C}$ for $20 \mathrm{~min}$. After the reaction mixture was quenched by the addition of water $(1 \mathrm{~mL})$, the methyl ester derivatives were extracted with $\mathrm{n}$-hexane $(2 \mathrm{~mL})$ and then analyzed by GC-MS with a HP-5 column with the oven temperature programmed from $90{ }^{\circ} \mathrm{C}$ (held for $3 \mathrm{~min}$ ) to $240{ }^{\circ} \mathrm{C}$ at $5{ }^{\circ} \mathrm{C} \cdot \mathrm{min}^{-1}$ (Fukuoka et al. 2008).

\subsubsection{MALDI-TOF mass spectrometry (MALDI-TOFMS)}

Solutions of purified biosurfactant were analyzed using the dried-droplet sample preparation technique directly spotting $1 \mu \mathrm{L}$ of samples directly onto a polished steel MALDI Target, model MTP 384 (Bruker Daltonics, Germany). After drying the sample, $1 \mu \mathrm{L}$ of matrix solution (alpha-hydroxycinnaminic acid saturated solution in acetonitrile-methanol-water, 1:1:1) was added and allowed to air dry at room temperature.

MALDI-TOFMS spectra were performed using an UltrafleXtreme MALDI-TOF mass spectrometer (Bruker Daltonics, Germany) operating in the refraction mode at an accelerating voltage of $22.5 \mathrm{kV}$. Mass spectra were acquired in $\mathrm{m} / \mathrm{z}$ range of $700-3500$ with ions generated from Smartbeam ${ }^{\mathrm{TM}}$ laser irradiation using a frequency of $2000 \mathrm{~Hz}$, 
a lens $7 \mathrm{kV}$ and the delay time was $110 \mathrm{~ns}$. Matrix-suppression was set to $500 \mathrm{Da}$, and the mass spectra were generated by averaging 1,500 laser shots. The laser intensity was set just above the threshold for ion production. External calibration was performed by using the $[\mathrm{M}+\mathrm{H}]+$ signals of Angiostin II, Angiostin I, Substance P, Bombesin, ACTH_clip(1-17), ACTH_clip(18-39), Somatostin(28) (Peptide calibration standard Bruker Daltonics, Bremen, Germany). The peptide mixture was dissolved in TA50 solvent (mixture of acetonitrile and $0.1 \%$ trifluoroacetic acid - volume ratio 1:1) (Fukuoka et al. 2008)

\subsubsection{Nuclear Magnetic Resonance (NMR)}

NMR analysis was carried out by dissolving the samples in deuterated chloroform $\left(\mathrm{CDCl}_{3}\right)$ and using an Agilent DD2 spectrometer at the Brazilian National Biosciences Laboratory (LNBio/CNPEM), operating at a ${ }^{1} \mathrm{H}$ Larmor frequency of 499.726 MHz. The coupling constants were measured in hertz $(\mathrm{Hz})$ and the chemical shifts $\left({ }^{1} \mathrm{H}, \delta{ }^{13} \mathrm{C}\right)$ ascribed in ppm, which were related to tetramethylsilane (TMS, $\left.\delta-0\right)$. The purified MEL was lyophilized. Then $\approx 30 \mathrm{mg}$ was diluted in $700 \mu \mathrm{L}$ of $\mathrm{CDCl}_{3}$ for data acquisition. 2D homo- and heteronuclear spectra such as COSY ( ${ }^{\mathrm{n}} \mathrm{J}_{\mathrm{H}-\mathrm{H}}$, scalar), NOESY ( ${ }^{\mathrm{n}} \mathrm{J}_{\mathrm{H}-\mathrm{H}}$, dipolar), HSQC $\left({ }^{1} \mathrm{~J}_{\mathrm{H}-\mathrm{C}}\right.$, scalar) e HMBC $\left({ }^{\mathrm{n}} \mathrm{J}_{\mathrm{H}-\mathrm{C}}\right.$, scalar $)$ were also performed (Fukuoka et al. 2007a, 2007b, 2008).

\section{Results and discussion}

\subsection{Determination of MEL concentration}

MEL have 4 homologues -A, -B, -C and -D (Fig. 2). MEL have two fatty acids in their chemical structure (Fig. 1b), these fatty acids vary from $\mathrm{C}_{8}$ to $\mathrm{C}_{14} \approx 86.6 \%$ 
(Fukuoka et al. 2007b; Morita et al. 2009a). Thus, two molecules of MEL that have different molecular weights due to, exclusively, the dual fatty acid chain lengths, could be grouped as the same homologue $(-\mathrm{A},-\mathrm{B},-\mathrm{C}$ or $-\mathrm{D})$ - as already mentioned MEL homologues are defined, exclusively, based on the acetylation in mannose (Figures 1-2). In other words, the type of fatty acids does not affect the classification of MEL homologues (Hubert et al. 2012).

To the best of our knowledge, only normal phase - silica column (Sajna et al. 2013, Recke et al. 2013, Konishi et al. 2011, Faria et al. 2014, Morita et al. 2015b) or droplet counter-current chromatography (Hubert et al. 2012) have been used for separation and further identification of MEL. However, MEL are hydrophobic compounds with high hydrophilic/lipophilic balance $(\mathrm{HLB}=8.8)$; (surfactants with HLB $<10$ are not water soluble). Thus, normal phase chromatography seems not as suitable for separation of MEL, mainly, due to the low resolution for MEL homologues and the restriction to inject water soluble samples. Also there is a need for solvent extraction of MEL from the culture medium before injection into the normal phase column; also the solvent extraction leads to some product losses and hence quantification error (Kim et al. 2002).

We describe here for the first time the analysis of MEL using a reverse phase column $(\mathrm{C}-18)$. This led to the identification of 4 peaks of MEL-B (standard) $\approx 11,16$, 23 and 25 minutes . Each peak corresponds to MEL-B homologues with different fatty acids.

\subsection{Bioreactor bioprocess}


The cell growth and biosurfactant production over the fermentation period are shown in Figure 4. The biosurfactant production here was monitored in terms of surface tension (ST) measurements..

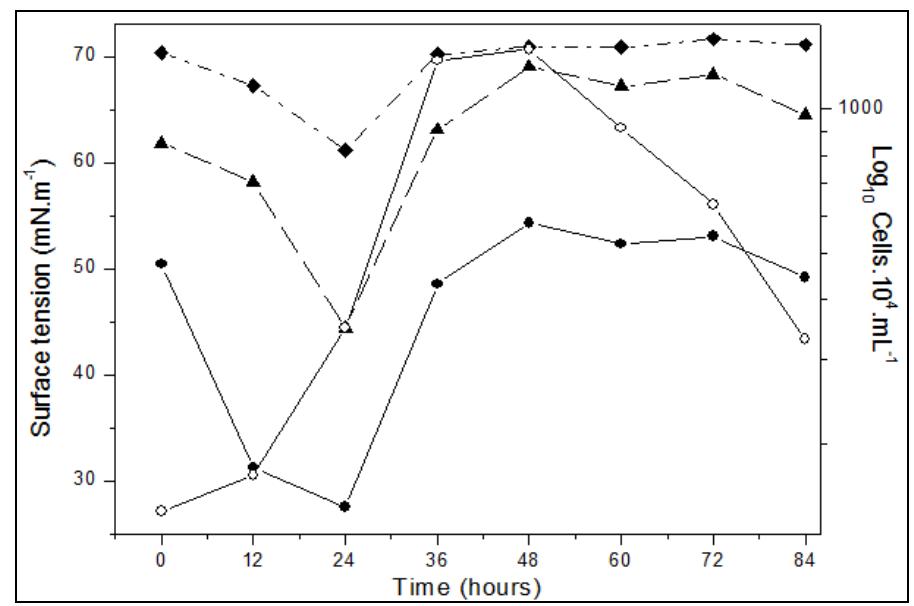

*Error bars were deliberately hidden

Figure 4. Culture medium - bioreactor experiments: ST $(-\bullet-)$, CMD-1 (- - $\bullet--)$,

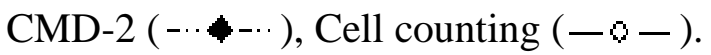

The fastest exponential cell growth occurred between 24 to $36 \mathrm{~h}$. This was expected, since at $24 \mathrm{~h}$, the aeration and agitation were increased from $0.04 \mathrm{vvm}$ and $100 \mathrm{rpm}$ respectively to 0.08 and $150 \mathrm{rpm}$. The stationary phase was reached at $36 \mathrm{~h}$, which is $12 \mathrm{~h}$ earlier than in the flask fermentation (data from the flask fermentations not shown). This difference is associated to better aeration conditions (compared to flask fermentation) in the bioreactor (more efficient transfer of oxygen, due to beter of agitation and better control of temperature). In addition, compared to the flask fermentation, the cell concentration was slightly lower in the bioreactor; probably due to some biomass loss in the foam during the biosurfactant recovery.. 
In the firsts $24 \mathrm{~h}$ of fermentation, the ST in the culture medium decreased from about 50 to $26 \mathrm{mN} \cdot \mathrm{m}^{-1}$ and this was ascribed to an increase in biosurfactant production. Then, the $\mathrm{ST}$ incresead to $\approx 52 \mathrm{mN} \cdot \mathrm{m}^{-1}$ at $48 \mathrm{~h}$. In fact, this can be associated with the removal of the biosurfactant from the liquid medium with the foam overflow. After $24 \mathrm{~h}$ the aeration and agitation were increased and consequently the foam formation increased which led to an increase in the removal of the biosurfactant from the medium and hence increased ST..

In order to avoid the recovery of an 'impure' foam with a high proportion of proteins from cassava wastewaterthe foam collected in the first $12 \mathrm{~h}$ was discarded (only the foam collected from 24 to $84 \mathrm{~h}$ was considered). The highest volumes of foam were obtained at $24 \mathrm{~h}(256 \mathrm{~mL}), 36 \mathrm{~h}(258 \mathrm{~mL})$ and $48 \mathrm{~h}(283 \mathrm{~mL})$ and then decreased to $160 \mathrm{~mL}$ at $60 \mathrm{~h}, 73 \mathrm{~mL}$ at $72 \mathrm{~h}$ and $26 \mathrm{~mL}$ at $84 \mathrm{~h}$. Thus, the total collapsed foam recovered per batch was $1000 \mathrm{~mL}$. Since $3 \mathrm{~L}$ of culture medium were used the foam recovered represents around $33 \%$, that is, an excellent evidence of good biosurfactant production.

During the process in the bioreactor, $\mathrm{pH}$ ranged from $\approx 5$ to 8 . Initially, the glucose concentration (mg. $\left.\mathrm{dL}^{-1}\right)$ was at $685(0 \mathrm{~h})$ and decreased (196) until $36 \mathrm{~h}$. Then a higher concentration was observed $343(48 \mathrm{~h})$ and it decreased again until the end of the bioprocess. This trend indicates that $P$. tsukubaensis is an amylase producer, which began to produce it when glucose is at low concentration (hydrolyzed starch remains in the culture medium). Konishi et al. (2011) described the glucose consumption during the production of MEL, which reached $0 \mathrm{~g} . \mathrm{L}^{-1}$, although the culture medium was composed by a mixture of carbon sources, olive oil and yeast extract. It is worth noting 
that yeast extract has peptone and amino acids that can be used as carbon source (Yan et al. 2012).

The ST measurements of the collapsed foam samples over the fermentation period are shown in Fig 5.

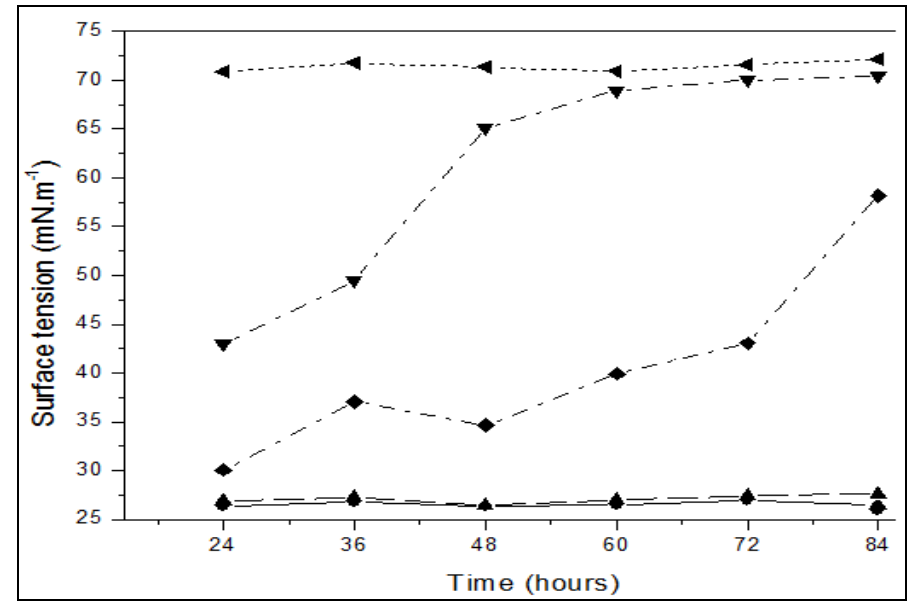

*Error bars were deliberately hidden

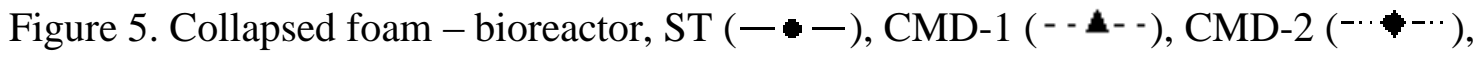

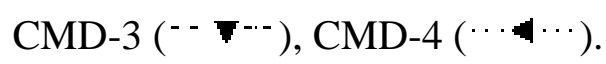

From 24 to $84 \mathrm{~h}$, the ST and CMD-1 and CMD-4 data of collapsed foam were constant. The first two indicated that the biosurfactant concentration was higher than the CMC - which result in constant ST measurements, whereas the CMD-4 (dilution of 10,000 times) had a ST similar to that of water $\left(\approx 72 \mathrm{mN} \cdot \mathrm{m}^{-1}\right)$ which shows that the concentration of biosurfactant was very low..

On the other hand, the CMD-2 and CMD-3 values changed during the bioprocess. Both analyses followed the same trend, the lowest ST measurements, that is highest concentrations of biosurfactant, were obtained from 24 to $48 \mathrm{~h}$. 
As detailed by Arutchelvi et al. (2008) and Yu et al. (2015), the ST at the CMC $(\gamma$-сMC $)$ of MEL homologues are: MEL-A $28.4 \mathrm{mN} . \mathrm{m}^{-1}$; MEL-B $28.2 \mathrm{mN} . \mathrm{m}^{-1}$; MEL-C 25.1, 24.2, $30.7 \mathrm{mN} . \mathrm{m}^{-1}$, whereas, Sajna et al. (2013), reported that $\gamma$-CMC of MEL-C from $P$. siamensis $33 . \mathrm{mN} . \mathrm{m}^{-1}$.

Thus, the obtained values are characteristic of MEL and follow the same trend as the ST - (Fig. 4). It is worth noting that, the foam may be composed, mostly, by MEL and proteins. The latter are also surface active and will contribute to the reduction of surface tension although their concentration in the medium should not change as much as that of the biosurfactant.

Therefore, cassava wastewater was a good culture medium for biosurfactants production from $P$. tsukunbaensis. The ST values of both culture medium and collapsed foam provided strong evidence that the foam was composed by MEL and this was further confirmed by other analysis (NMR, HPLC, CG-MS).

\subsubsection{Production of MEL - kinetics and yield}

In this study, the MEL recovered in the foam, after lyofilization (14.01 g), had a purity of $27 \%\left(\mathrm{w}^{-1} \mathrm{w}^{-1}\right)$, which means that $1.26 \mathrm{~g}$ of MEL per liter of culture medium were produced.

The analyses of MEL production by HPLC, followed the same trend than surface activity measurements and volume of foam recovered, that is, the higher the biosurfactant production, the higher the volume of foam. The purity levels were higher at the beginning of fermentation: $24 \mathrm{~h}-38 \%$ (256 mL of foam), $36 \mathrm{~h}-45 \%$ (258 mL) and 48 $\mathrm{h}-51 \%(283 \mathrm{~mL})$. Then it decreased, $60 \mathrm{~h}-33 \%(161 \mathrm{~mL}), 72 \mathrm{~h}-27 \%(73 \mathrm{~mL})$ and 84 
$\mathrm{h}-25 \%(40 \mathrm{~mL})$. Thus, confronting these data with cell counting, the biosurfactant production occurred mostly during the exponential phase.

To the best of our knowledge, Morita et al. (2009a) described for the first time MEL production using water-soluble traditional fermentable carbohydrates. They reported the production of MEL-A from $P$. antarctica JCM 10317 using glucose and sucrose as carbon sources, 1.61 and 1.94 g. $\mathrm{L}^{-1}$, respectively, also the production of MEL-C from $P$. siamensis CBS 9960, using 1.08 and 1.94 g.L $\mathrm{L}^{-1}$ of glucose and sucrose, respectively. Later, Faria et al. (2014) studied the production of MEL from P. antarctica PYCC $5048^{\mathrm{T}}$, P. aphidis PYCC $5535^{\mathrm{T}}$ and P. rugulosa PYCC $5537^{\mathrm{T}}$ by the use of three different carbon sources, glucose, xylose or arabinose, separately that presented similar maximum specific growth rates. Although a lag phase was observed only with xylose and arabinose. The use of hydrophilic carbon sources is advantageous (compared to hydrophobic carbon sources - e.g vegetal oils), since the purification is easier. Thus, hydrophilic carbon sources should be used even if lower yield is reached (Morita et al. 2015a).

Arutchelvi et al. (2008) described that production of MEL as non-growth associated bioprocess. Faria et al. (2014), detailed that the production of MEL, using water-soluble (hydrophilic) carbon source, occurred mainly in stationary phase. However in this study, the production of MEL was relatively growth associated, maybe due to the use of $P$. tsukunbaensis instead of other Pseudozymas species and soluble carbon source rather than the usual hydrophobic carbon sources (olive and soybean oils).

Sophorolipids and MEL are the only biosurfactants produced by microorganisms that reach yields as high as 100 g.L $\mathrm{L}^{-1}$ for MEL and 300 g.L. $\mathrm{L}^{-1}$ for 
sophorolipids (Hubert et al. 2012, Sajna et al. 2013). To cite an instance, Konishi et al. (2011) reported MEL production of 49.2 g.L-in a batch bioprocess using a culture medium with a mixture of carbon sources containing 10 g.L $\mathrm{L}^{-1}$ of yeast extract, 100 g.L $\mathrm{L}^{-1}$ of glucose and 100 g.L $\mathrm{L}^{-1}$ of olive ${ }^{1}$; the authors enhanced the production of MEL to 129 g.L $\mathrm{L}^{-1}$ (volumetric productivity of 18.4 g. $\mathrm{L}^{-1} \cdot \mathrm{day}^{-1}$ ) using a feed-batch system. Sajna et al. (2013) obtained 34 g.L L $^{-1}$ of MEL production with 3.7 g.L.- day $^{-1}$ using soybean oil (8\% $\left.\mathrm{W} . \mathrm{v}^{-1}\right)$, yeast extract and minerals as culture medium.

Yu et al. (2015) investigated the production of MEL by genus Pseudozyma and obtained different production for the species: P. aphilis (165 g. $\left.\mathrm{L}^{-1}\right)$, P. rugulosa $(142$ g.L $\left.\mathrm{L}^{-1}\right)$, P. Antarctica (140 g.L $\left.\mathrm{L}^{-1}\right)$, P. parantarctica (106.7 g.L.'-1 ), P. hubeiensis (76.3 g.L $\left.{ }^{-1}\right)$ P. tsukunbaensis (73.1 g.L $\left.\mathrm{L}^{-1}\right)$ P. Antarctica $\left(26.0\right.$ g.L $\left.\mathrm{L}^{-1}\right)$, P. siamensis (18.5 g.L$\left.{ }^{1}\right)$ and $P$. graminicola $\left(10\right.$ g. $\left.\mathrm{L}^{-1}\right)$.

\subsection{Purification of MEL by ultrafiltration process}

\subsubsection{Purity of MEL - lyophilized foam}

The foam collected from each fermentation process (F-2, F-3 and F-4) ), after centrifugation (to remove biomass) and lyophilization (powder) showed a purity (HPLC) of approximately $30 \%(\mathrm{w} / \mathrm{w})$. The main impurity was proteins (see ultrafiltration process), which most likely came from cassava wastewater and also from the $P$. tsukubaensis itself. In addition, the purity of lyophilized foam in terms of protein $(\mathrm{P} P)$ was 0.34 (Table 1).

\subsubsection{Small scale ultrafiltration}


The feed solutions prepared with the lyophilized foam of F-2 (two samples) showed a unimodal distribution: $\mathrm{d}=1220 \mathrm{~nm}$ at $610.74 \mathrm{mg} . \mathrm{L}^{-1}$ of MEL (experiment 1 ) and $\mathrm{d}=1754 \mathrm{~nm}$ at $502.71 \mathrm{mg} . \mathrm{L}^{-1}$ of MEL (experiment 2). These particles correspond to micelles of MEL that were mostly (80\%) retained during the ultrafiltration . Additionally, more than $95 \%$ of proteins were found in the permeate (Table 1). These results indicated the remarkable purification process with a high MWCO membrane (100 kDa PES) which resulted in high flux and minimized fouling. Moreover, MEL was purified from low molecular weight compounds and proteins only in one step of ultrafiltration as opposed to two steps as in the purification of surfactin (Isa et al. 2007). The difference between the ultrafiltration of MEL and surfactin, is due to MEL aggregating into bigger micelles than surfactin; also, MEL is a nonionic biosurfactant whereas surfactin is an anionic biosurfactant, thus surfactin may interact by electrostatic interactions with proteins making the purification process harder.

Therefore, due to these noteworthy outcomes the process was scaled up to 500 $\mathrm{mL}$ (250 $\mathrm{mL}$ working volume).

\subsubsection{Bench-top ultrafiltration - scale up}

The ultrafiltration at bench-top scale took 45 minutes and reduced the initial volume of feed $(250 \mathrm{~mL})$ to $25 \mathrm{~mL}$ running it in recirculation mode. During the first 25 minutes, the flux significantly decreased from 90 to $55 \mathrm{~L} \cdot \mathrm{m}^{-2} \cdot \mathrm{h}^{-1}$. Then, in the last 20 minutes, the flux reduced from 55 to $45 \mathrm{~L} \cdot \mathrm{m}^{-2} \cdot \mathrm{h}^{-1}$ (Fig. 6). 


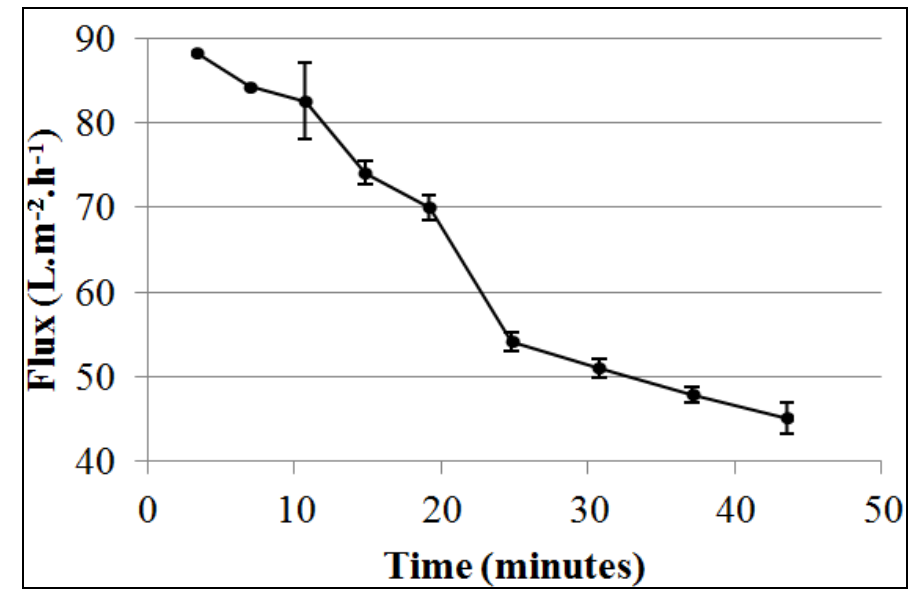

Figure 6. Flux of ultrafiltration (-).

Probably the main factor for the reduction of flux was the fouling occurred due to the presence of proteins. It is worth noting that there are two sources of proteins, one P. tsukubaensis itself and the other cassava wastewater; this wide range of proteins (large, small, etc) may interact with the membrane in different ways.

In recirculation mode (the retentate returns as feed), the initial volume of feed/retentate decreased (from $250 \mathrm{~mL}$ to $25 \mathrm{~mL}$ ). On the other hand, the volume of permeate increased, that is, the volume of feed/retentate and permeate are inversely proportional. The analysis of Figure 7 indicates that the concentration of MEL in retentate) increased from 294.7 to $859.52 \mathrm{mg} . \mathrm{L}^{-1}$ which proved that PES-100 membrane retained MEL micelles. On the contrary, the concentration of protein in the retentate significantly decreased which indicated that they were permeated. This is in agreement with the observation that the concentration of proteins in the permeate was relatively constant because the volume of permeate increased together with the amount of protein permeated. 


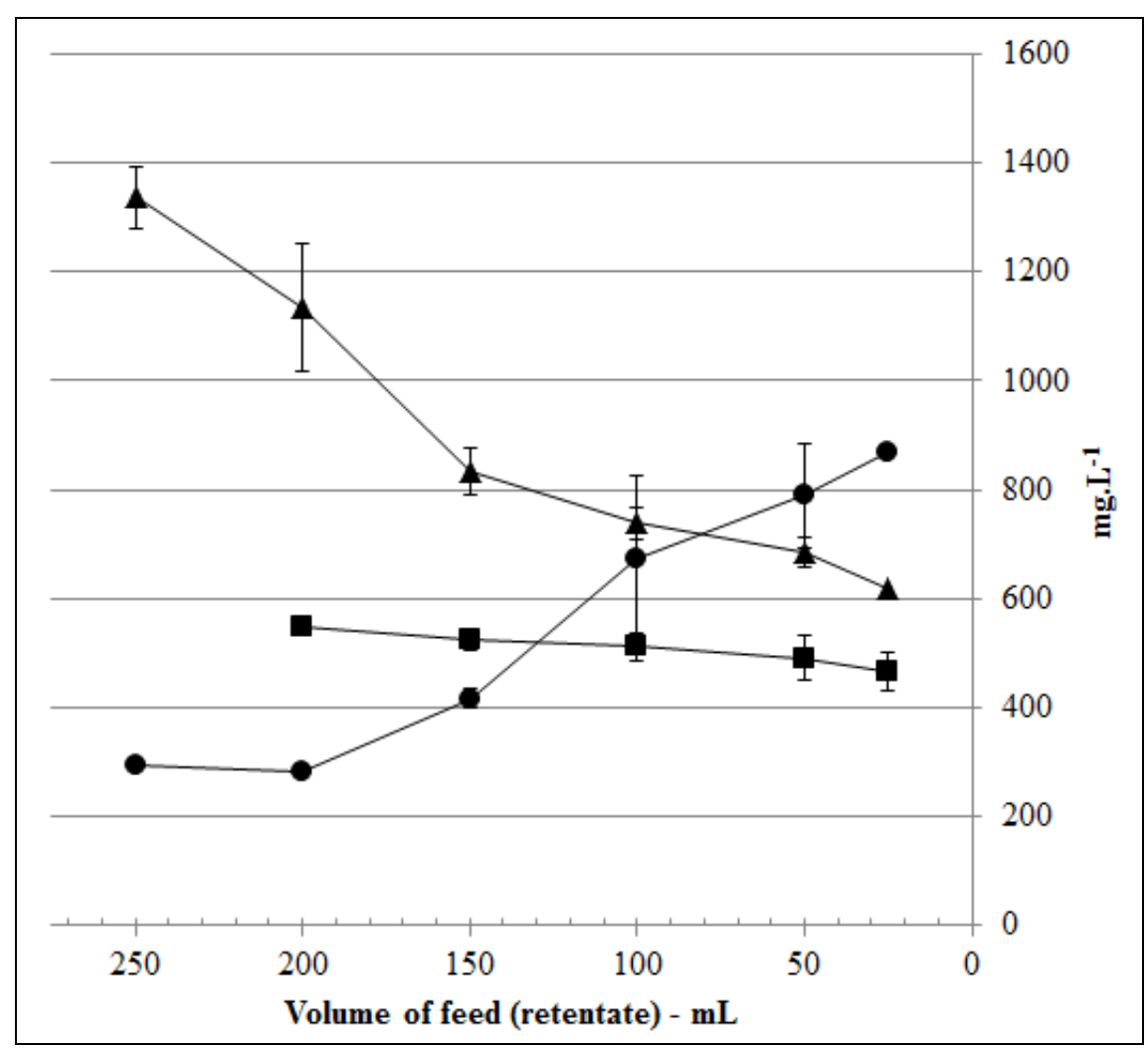

Figure 7. Concentration of MEL - feed/retentate $\left({ }^{\bullet}-\right)$, Concentration of protein feed/retentate $\left(\boldsymbol{\star}^{-}\right)$; Concentration of protein - permeate $\left({ }^{-}\right)$.

Therefore, in agreement with the small scale ultrafiltration process, the selfaggregation properties of MEL enable its purification by membrane filtration in one step. The final product resulted in a highly concentrated solution of MEL $(25 \mathrm{~mL} \approx 860$ mg. $\mathrm{L}^{-1}$ ) at high purity. This is summarized in Table 1 .

Table 1. Summary of biosurfactant and protein concentration $\left(\mathrm{mg} \cdot \mathrm{L}^{-1}\right)$ in feed (foam) and retentate of ultrafiltration for small scale (centrifugal device) and scale up (benchtop UF) experiments.

\section{Small scale $^{* *} \quad$ Scale up ${ }^{* *}$}

Feed Retentate Feed Retentate




\begin{tabular}{ccccc}
\hline${ }^{\top} \mathbf{M C}$ & 556.72 & 440.03 & 294.7 & 859.52 \\
${ }^{*} \mathbf{P C}$ & 1622.03 & 70.86 & 1338.46 & 1543.36 \\
${ }^{\dagger} \mathbf{P P}$ & 0.34 & 0.86 & 0.18 & 0.58 \\
\hline
\end{tabular}

$\dagger$ MEL concentration

* Protein concentration

$\dagger$ Purity in term of protein

** Average of duplicate observations

The purity, in terms of protein (Eq. 2) increased from 0.34 to 0.86 (in small scale ultrafiltration experiments) and from 0.18 to 0.58 (in scale up experiments) (Table 1), ie in both experiments a three fold increase in purity was achieved. Overall, in the entire process, production plus purification, $\approx 215 \mathrm{mg}$ of purified MEL were produced.

3.4. Chemical identification of purified MEL - Fatty acid profile, MALDITOFMS, NMR and Infrared.

The CG-MS analysis showed the presence of C8:0; C10:0; C12:1; C12:0; C14:1 and $\mathrm{C} 18: 1$, in which $\mathrm{C} 8: 0, \mathrm{C} 12: 1$ and $\mathrm{C} 14: 1$ were the main peaks (Fig. 8), which is relatively similar to that described by Sajna et al. (2013), C14:1, C16:0, C16:1 and also to Fukuoka et al. (2008) C12 and C14 molecules. 


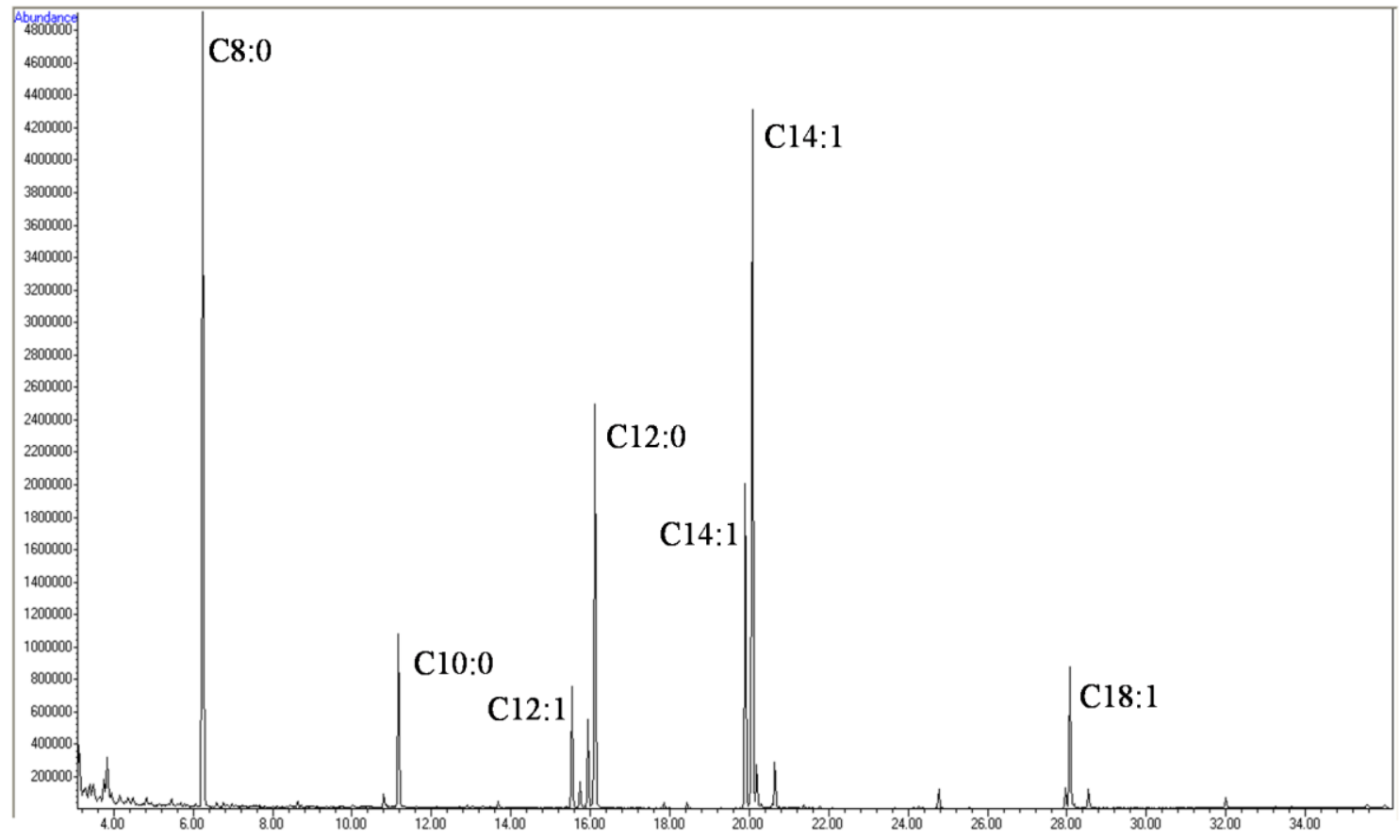

Figure 8. Gas cromatography of MEL produced from P. tsukubaensis - fatty acid profile

Later, Fukuoka et al. (2011) identified the presence of C8:0, C10:0; C12:0, C12:1, C14:0, C14:1 and C14:2. Although, Fan et al. (2014) described the presence, mainly, of longer fatty acid chains C18:0, C18:1 and C20:0. Finally, Fan et al. (2014) detailed that the main fatty acids were C8:0, C18:0, C18:1 and C20:0, that is, a wide range from short to long chains. 


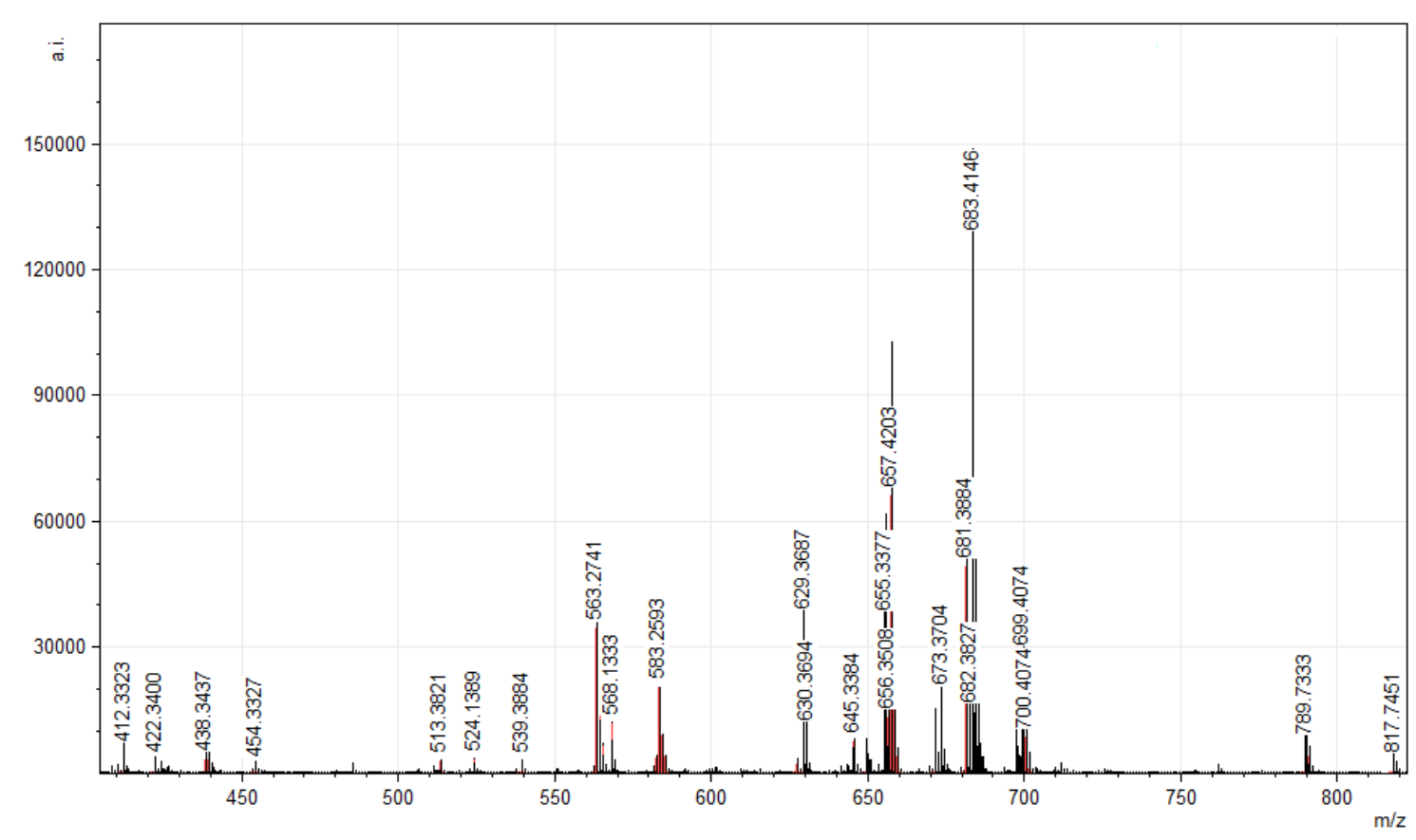

Figure 9. MALDI-TOFMS spectrum of MEL produced from P. tsukubaensis

MALDI-TOFMS has high sensitivity and fast measurement for the identification of molecular masses of MEL homologues, and in combination with NMR and GC-MS analysis can be used to elucidate the structure of MEL in detail. The combination of analysis for chemical identification is especially true for molecules that are chemically complex (composed by fatty acids, sugar, peptides etc.) such as MEL.

In this sense, CG-MS, infra-red, NMR and MALDI-TOFMS analysis were combined in order to confirm the chemical structure of the purified MELB (retained after ultrafiltration).

P. tsukubaensis produced many variants of MEL, in which the peaks with highest intensity were 683.41 and $657.42 \mathrm{~m} / \mathrm{z}$ (Fig. 9). The same peaks were reported by Fukuoka et al. (2008). Morita el al. (2009b) reported that peak $657.1 \mathrm{~m} / \mathrm{z}$ (Fig. 9 second most intense peak) corresponded to MEL-B containing fatty acid chains of C8:0 and C12:0. According to GC-MS data C8:0, C12:1 and C14:1 were the main peaks 
obtained. Therefore, the peak $683.41 \mathrm{~m} / \mathrm{z}$ was associated to C8:0 and C14:1 (difference of $26 \mathrm{~m} / \mathrm{z}$ can be related to two extra carbons with one unsaturation) as the pair of fatty acids of MEL. As shown in Fig. 9, other peaks are probably related to chain length of fatty acids C-2' and C-3' of mannose (variants of MEL) as demonstrated also by GCMS. Thus, MALDI-TOFMS analysis showed very high similarity to previous reports, which strongly indicated the production of MEL-B or MEL-C.

The analysis of infrared data indicated high absorption on $3400(\mathrm{O}-\mathrm{H}), 1730$ $(\mathrm{C}=\mathrm{O}), 1240(\mathrm{C}-\mathrm{O}), 1075$ (-O-), which is very similar to that reported by Kitamoto et al. (1990).

In order to confirm the structure of the homologue MEL-B ${ }^{1} \mathrm{H},{ }^{13} \mathrm{C}$ nuclear magnetic resonance (NMR) and two-dimensional NMR analysis, such as COSY $\left({ }^{1} \mathrm{H}-{ }^{1} \mathrm{H}\right.$ correlation spectroscopy), HSQC- ${ }^{13} \mathrm{C}-\mathrm{DEPT}$ (heteronuclear single quantum coherence with DEPT, ${ }^{1} \mathbf{J}_{\mathrm{C}-\mathrm{H}}$ ), HMBC (heteronuclear multiple bond correlation, ${ }^{\mathrm{n}} \mathrm{J}_{\mathrm{C}-\mathrm{H}}$ ), and the nuclear effect overhauser (NOE) were performed. The ${ }^{1} \mathrm{H}$ NMR chemical shifts, multiplicities and coupling constants are shown in Table 2, whereas the ${ }^{13} \mathrm{C}$ NMR data are in Table 3.

The ${ }^{1} \mathrm{H}$ NMR data showed similar patterns to those already reported (Morita et al. 2015b, Fukuoka et al. 2007a, 2007b, 2008, Recke et al. 2013, Sajna et al. 2013, Fan et al. 2014, Faria et al. 2014), although significant differences were observed. The signal at $4.76 \mathrm{ppm}$ was assigned to anomeric hydrogen $\mathrm{H}-1$, whereas, doublet at 5.49 ppm and doublet of double doublets at $4.95 \mathrm{ppm}$ were assigned to $\mathrm{H}-2$ and $\mathrm{H}-3$, respectively and estimated as hydrogens bonded to esterified carbons C-2 and C-3 of the mannose. Additionally, two doublets of doublets, one at $4.41 \mathrm{ppm}(\mathrm{J}=12.13$ and 5.22 $\mathrm{Hz})$ and the second one at $4.46 \mathrm{ppm}(\mathrm{J}=12.41$ and $2.54 \mathrm{~Hz})$ were observed which were 
assigned to diastereotopic protons H-6a and H-6b. Moreover, a singlet with integral for three hydrogens was observed at $2.14 \mathrm{ppm}$ and was assigned as the methyl bonded to acetyl group.

The triplets $(6.03 \mathrm{~Hz})$ at $0.88 \mathrm{ppm}$ and with integral value to six hydrogens were assigned to two methyl-end carbon chain lipids. These results strongly indicate the presence of two acyl groups of fatty acids and an acetyl group. The coupling constants and the correlations observed in the COSY corroborated the correct assignments of the protons and the stereochemistry of the chiral centers.

A shift of $\mathrm{C}-1$ of the D-mannose unit to $99.10 \mathrm{ppm}$ indicates that the $\mathrm{O}$ glycosidic bond was between $\mathrm{C}$-1 of $D$-mannose to meso-erythritol unit, which was confirmed by the HMBC correlations (Tables 2 and 3). On the ${ }^{13} \mathrm{C}$ NMR spectrum, three peaks derived from carbonyl groups were assigned at 171.64, 173.59 and 173.40 ppm (Table 3). HMBC analysis showed that each of these carbonyl carbons was correlated with one of the protons of $D$-mannose: H-6, H-2, and $\mathrm{H}-3$, respectively. Moreover, the methyl protons at 2.14 ppm showed correlation to carbonyl carbon at $171.64 \mathrm{ppm}$.

Therefore, the NMR spectra analysis confirmed that the purified sample had the structure of MEL-B, where $\mathrm{R}_{1}(\mathrm{C}-2)$ and $\mathrm{R}_{2}(\mathrm{C}-3)$ are acyl groups, $\mathrm{R}_{3}$ is a hydroxyl group and $\mathrm{R}_{4}$ is an acetyl group (Fig. 10). It was also observed a minority second stereoisomer, between 8 to $10 \%$ by ${ }^{1} \mathrm{H}-\mathrm{NMR}$ spectrum (Fig. 11). 


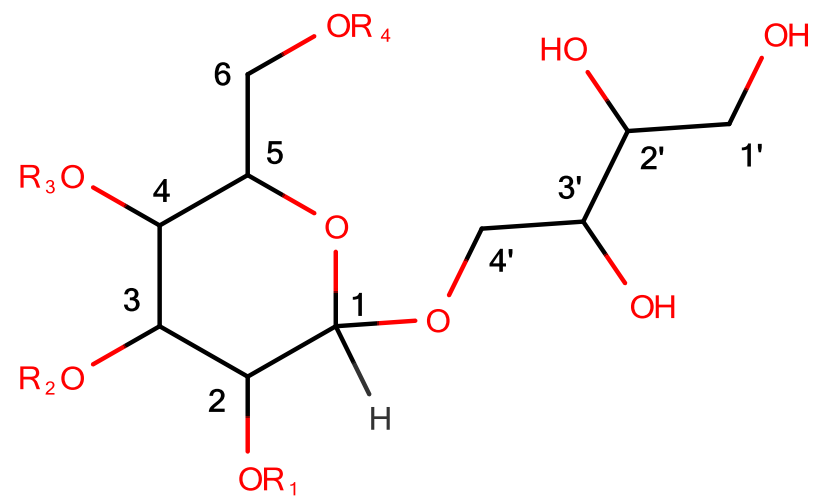

$\mathrm{R}_{1}$ and $\mathrm{R}_{2}=$ Fatty acids; $\mathrm{R}_{3}=\mathrm{H} ; \mathrm{R}_{4}=-\mathrm{C}(\mathrm{O}) \mathrm{CH}_{3}$

Figure 10. Chemical structure of purified sample (MEL-B).

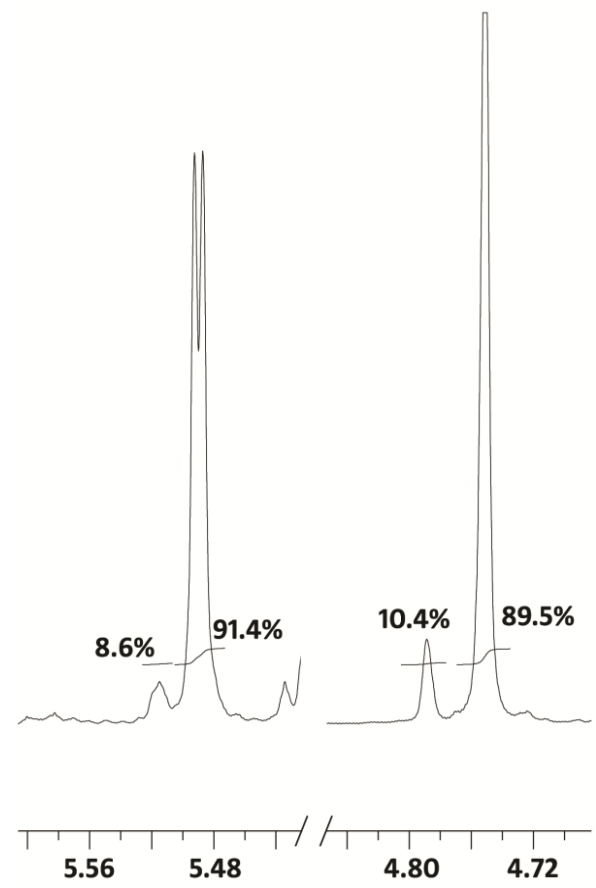

Figure 11. ${ }^{1} \mathrm{H}$ NMR data in $\mathrm{CDCl}_{3}$ of purified sample and the presence of a second stereoisomer between $8 \%$ and $10 \%$, which was based on signals of protons H-2 (5.49 ppm) and H-1 (4.76 ppm). 
Table 2. ${ }^{1} \mathrm{H}$ NMR data in $\mathrm{CDCl}_{3}$ of purified sample (s: singlet, d: doublet, dd: doublet of doublet, ddd: doublet of double doublets; t: triplet, m: multiplet, brs: broad signal. $\mathrm{R}_{1}$ and $R_{2}$ are fatty acids, $R_{3}$ is hydroxyl and $R_{4}$ is acetyl group.

\begin{tabular}{|c|c|c|c|c|c|}
\hline $\begin{array}{c}\text { Functional } \\
\text { groups }\end{array}$ & & $\begin{array}{c}\delta^{1} \mathbf{H}(\mathbf{p p m}) \text { and } \\
\text { multiplicities }\end{array}$ & $\begin{array}{c}\text { Couplingconstants } \\
(\mathrm{J} \text { in } \mathrm{Hz})\end{array}$ & $\begin{array}{c}\text { COSY } \\
\text { correlations }\end{array}$ & $\begin{array}{c}\text { HMBC } \\
\text { correlations }\end{array}$ \\
\hline \multicolumn{6}{|l|}{ Sugar } \\
\hline \multicolumn{6}{|l|}{$D$-mannose } \\
\hline H-1 & & 4.76 (brs) & $<2,0$ & $\begin{array}{l}\mathrm{H}-2, \mathrm{H}-3, \mathrm{H}- \\
\text { 4'a, H-4'b }\end{array}$ & C-2, C-3, C-4' \\
\hline H-2 & & 5.49 (d) & 3.31 & $\mathrm{H}-1, \mathrm{H}-3$ & $\begin{array}{c}\mathrm{C}-1, \mathrm{C}-3, \mathrm{C}-4, \\
173,59\left(\mathrm{R}_{1}\right)\end{array}$ \\
\hline H-3 & & 4.95 (ddd) & $\begin{array}{c}10.04,3.35 \text { and } \\
1.46\end{array}$ & H-1, H-2, H-4 & $\begin{array}{c}\mathrm{C}-1, \mathrm{C}-2, \mathrm{C}-4, \\
173,40\left(\mathrm{R}_{2}\right)\end{array}$ \\
\hline H-4 & & $3.78(\mathrm{~m})$ & & H-3, H-5 & C-3, C-5, C-6 \\
\hline H-5 & & $3.59(\mathrm{~m})$ & & $\begin{array}{c}\mathrm{H}-4, \mathrm{H}-6 \mathrm{a}, \mathrm{H}- \\
6 \mathrm{~b}\end{array}$ & $C-4, C-6$ \\
\hline H-6a & & $4.41(\mathrm{dd})$ & $12.13,5.22$ & H-5, H-6b & $\begin{array}{c}\mathrm{C}-4, \mathrm{C}-5,171,64 \\
\left(\mathrm{R}_{4}\right)\end{array}$ \\
\hline H-6b & & $4.46(\mathrm{dd})$ & $12.41,2.54$ & H-5, H-6a & $\begin{array}{c}\mathrm{C}-4, \mathrm{C}-5,171,64 \\
\left(\mathrm{R}_{4}\right)\end{array}$ \\
\hline $\begin{array}{l}\text { Hydroxyls } \\
\text { meso- }\end{array}$ & $\mathbf{R}_{3}$ & $2.82-3.49$ (brs) & & & \\
\hline \multicolumn{6}{|l|}{ Erythritol } \\
\hline H-1'a & & $3.66-3.73(\mathrm{~m})$ & & $\mathrm{H}-1$ 'b, H-2' & C-2', C-3' \\
\hline H-1'b & & $3.56-3.62(\mathrm{~m})$ & & $\mathrm{H}-1$ ' a, H-2' & C-2', C-3' \\
\hline H-2' & & $3.56-3.62(\mathrm{~m})$ & & $\begin{array}{c}\mathrm{H}-1^{\prime}{ }^{\prime} \mathrm{a}, \mathrm{H}-\mathrm{l}^{\prime} \mathrm{b}, \\
\mathrm{H}-3^{\prime}\end{array}$ & $\mathrm{C}-1^{\prime}, \mathrm{C}-3^{\prime}, \mathrm{C}-4^{\prime}$ \\
\hline H-3, & & $3.69-3.75(\mathrm{~m})$ & & $\begin{array}{c}\mathrm{H}-2^{\prime}, \mathrm{H}^{-} 4^{\prime} \mathrm{a}, \mathrm{H}- \\
4^{\prime} \mathrm{b}\end{array}$ & $\mathrm{C}-1^{\prime}, \mathrm{C}-2^{\prime}, \mathrm{C}-4^{\prime}$ \\
\hline H-4'a & & $3.88(\mathrm{dd})$ & $11.17,5.34$ & $\begin{array}{c}\mathrm{H}-1, \mathrm{H}-3^{\prime}, \mathrm{H}- \\
4^{\prime} \mathrm{b}\end{array}$ & $\mathrm{C}-1, \mathrm{C}-2^{\prime}, \mathrm{C}-3$ ' \\
\hline H-4'b & & $3.93(\mathrm{dd})$ & $11.17,3.40$ & $\begin{array}{c}\mathrm{H}-1, \mathrm{H}-3^{\prime}, \mathrm{H}- \\
4^{\prime} \mathrm{a}\end{array}$ & $\mathrm{C}-1, \mathrm{C}-2^{\prime}, \mathrm{C}-3^{\prime}$ \\
\hline Hydroxyls & & $2.82-3.49(\mathrm{brs})$ & & & \\
\hline Acetyl & Chain & & & & \\
\hline$-\mathrm{CH}_{3}$ & $\mathbf{R}_{4}$ & $2.14(\mathrm{~s})$ & & & 171,64 \\
\hline \multicolumn{6}{|l|}{ Fatty acids } \\
\hline$-\mathrm{CH}_{3}$ & $\mathbf{R}_{1}, \mathbf{R}_{2}$ & $0.88(\mathrm{x} 2)(\mathrm{t})$ & 6.07 & & \\
\hline \multirow[t]{2}{*}{$-\mathrm{CO}-\mathrm{CH}_{2}-$} & $\mathbf{R}_{1}, \mathbf{R}_{2}$ & $2.30(\mathrm{~m})$ & & & $\begin{array}{c}173,40 \text { and } \\
173,59\end{array}$ \\
\hline & & $2.40(t)$ & 7.65 & & $\begin{array}{c}173,40 \text { and } \\
173,59\end{array}$ \\
\hline $\begin{array}{c}-\mathrm{CO}- \\
\mathrm{CH}_{2} \mathrm{CH}_{2-}^{-}\end{array}$ & $\mathbf{R}_{1}, \mathbf{R}_{2}$ & $1.57-1.70(\mathrm{~m})$ & & & $\begin{array}{c}173,40 \text { and } \\
173,59\end{array}$ \\
\hline$-\left(\mathbf{C H}_{2}\right)_{\mathbf{n}^{-}}$ & $\mathbf{R}_{1}, \mathbf{R}_{2}$ & $1.22-1.39(\mathrm{~m})$ & & & \\
\hline$-\mathrm{CH}=\mathrm{CH}-$ & $\mathbf{R}_{1}, \mathbf{R}_{2}$ & $5.20-5.44(\mathrm{~m})$ & & & \\
\hline
\end{tabular}


$-\mathrm{CH}=\mathrm{CH}-$

$\mathrm{CH}_{2}$ -

$\mathbf{R}_{\mathbf{1}}, \mathbf{R}_{\mathbf{2}} \quad 1.96-2.10(\mathrm{~m})$

$\delta^{1} \mathrm{H}$ : Chemical shift in ppm; Coupling constant $\left({ }^{\mathrm{n}} \mathrm{J}\right)$ in $\mathrm{Hz}$. 
Table $3 .{ }^{13} \mathrm{C}$ NMR data in $\mathrm{CDCl}_{3}$ (at $125 \mathrm{MHz}$ ) of purified sample. $\mathrm{R}_{1}$ and $\mathrm{R}_{2}$ are fatty acids, $R_{3}$ is hydroxyl hydrogen and $R_{4}$ is acetyl group.

\begin{tabular}{|c|c|c|}
\hline Functional groups & & $\delta^{13} \mathrm{C}(\mathrm{ppm})$ \\
\hline Sugar & & \\
\hline \multicolumn{3}{|l|}{$D$-mannose } \\
\hline C-1 & & 99.10 \\
\hline $\mathrm{C}-2$ & & 68.81 \\
\hline $\mathrm{C}-3$ & & 73.18 \\
\hline $\mathrm{C}-4$ & & 65.65 \\
\hline C-5 & & 74.47 \\
\hline C-6 & & 63.19 \\
\hline \multicolumn{3}{|l|}{ Meso-erythritol } \\
\hline $\mathrm{C}-1$ & & 63.65 \\
\hline $\mathrm{C}-2$ & & 71.87 \\
\hline $\mathrm{C}-3$ & & 71.30 \\
\hline C-4' & & 72.19 \\
\hline Acetyl group & Chain & \\
\hline$-\mathrm{CH}_{3}$ & $\mathrm{R}_{4}$ & 21.07 \\
\hline$-\mathrm{C}=\mathrm{O}$ & $\mathrm{R}_{4}$ & 171.64 \\
\hline
\end{tabular}

Fatty acids

$\begin{array}{ccc}-\mathrm{C}=\mathrm{O} \text { (in C-2) } & & 173.59 \\ -\mathrm{C}=\mathrm{O} \text { (in C-3) } & & 173.40 \\ -\mathrm{CH}_{3} & \mathrm{R}_{1}, \mathrm{R}_{2} & 14.33 \\ -\mathrm{CO}-\mathrm{CH}_{2}- & \mathrm{R}_{1}, \mathrm{R}_{2} & 34.19 \\ & & 34.02 \\ -\mathrm{CO}-\mathrm{CH}_{2} \mathrm{CH}_{2-} & \mathrm{R}_{1}, \mathrm{R}_{2} & 25.04 \\ -\left(\mathrm{CH}_{2}\right)_{\mathrm{n}^{-}} & \mathrm{R}_{1}, \mathrm{R}_{2} & 22.62-32.12 \\ -\mathrm{CH}=\mathrm{CH}- & \mathrm{R}_{1} \text { or } \mathrm{R}_{2} & 127.50-131.33 \\ -\mathrm{CH}=\mathrm{CH}-\mathrm{CH}_{2-} & \mathrm{R}_{1} \text { or } \mathrm{R}_{2} & 26.25\end{array}$

$\delta^{13} \mathrm{C}$ : Chemical shift in ppm; Multiplicities of the carbons were defined by HSQC-

DEPT spectrum.

\section{Conclusion and perspective}

Cassava wastewater is a feasible alternative culture medium to the production of MEL-B from $P$. tsukubaensis as productivities comparable to those obtained with other water-soluble $\mathrm{C}$ sources were obtained. Thus, the main advantages of this bioprocess are the use of a very low cost substrate and the water-solubility of cassava wastewater 
(easier purification). Regarding the purification, comparing with the traditional purification steps of MEL (ethyl acetate extraction followed by column chromatography), the recovery of MEL-B by foam overflow integrated with ultrafiltration is a remarkable strategy since it avoids the use of organic solvents which is aligned with the green chemistry concept, it is scalable and in principle more cost effective. Moreover the purification of MEL can be achieved in one UF step instead of two as in the case of other biosurfactants such as surfactin. The NMR analysis proved the exclusive production of MEL-B by $P$. tsukubaensis instead of other MEL homologues (-A, -C and -D). Moreover GC-MS confirmed the identification of MELB, C8:0 and 12:0 $(657 \mathrm{~m} / \mathrm{z})$ and C8:0 and C14:1 $(683 \mathrm{~m} / \mathrm{z})$ and also indicated the production of minority stereoisomers, about 8 to $10 \%$. This stereoisomer had a different erythritol orientation (never reported). In summary the main outcomes of this study were: (i) production of MEL-B using cassava wastewater, (ii) purification of MEL-B by foam fractionation followed by ultrafiltration, and (iii) a new analytical method for the quantification of MEL. Future research should focus on further optimization of production by supplementation of culture medium with hydrophobic compounds, its effects on the ultrafiltration process and applications of purified MEL-B for example, in skin care.

\section{Conflict of interest}

The authors declare no conflict of interest.

\section{Acknowledgements}

The authors are grateful to the São Paulo State Research Foundation (Fapesp) for their financial support, Brazilian Bioscience National Laboratory (institution of 
CNPEM) for RMN analysis and Chemical Engineering Department of the Polytechnic School of the University of São Paulo for MALDI-TOFMS analysis.

\section{References}

1. Andrade, C.J., Andrade, L.M., Bution, M.L., Dolder, M.A.H., Barros, F.F.C., Pastore, G.M, 2016a. Optimizing alternative substrate for simultaneous production of surfactin and 2,3-butanediol by Bacillus subtilis LB5a. Biocataly. Agricul. Biotechnol, 6, 209218.

2. Andrade, C.J., Barros, F.F.C., Andrade, L.M., Rocco, A.S., Sforça, M.L., Pastore, G.M., Jauregi, P, 2016b. Ultrafiltration based purification strategies for surfactin produced by Bacillus subtilis LB5A using cassava wastewater as substrate. J. Chem. Technol. Biotechnol., 2016b, DOI: 10.1002/jctb.4928

3. Andrade, C.J., Simiqueli, A.P.R., Lima, F.A., Silva, J.B., Andrade, L.M., Fai, A.E.C. Cassava wastewater as substrate in Biotechnological Process. In: Handbook of cassava: production, potential uses and recent advances. Clarissa Klein (editor). Nova Publisher, New York, 171-199, 2016c.

4. Arutchelvi, J.I., Bhaduri, S., Uppara., P.V., Doble, M., 2008. Mannosylerythritol lipids: a review. J. Ind. Microbiol. Biotechnol. 35, 1559-1570.

5. Chen, H-L., Chen, Y-S., Juang, R-S., 2007. Separation of surfactin from fermentation broths by acid precipitation and two-stage dead-end ultrafiltration processes. J. Membrane Sci. 299, 114-121. 
6. Chen, H-L., Chen, Y-S., Juang, R-S., 2008. Recovery of surfactin from fermentation broths by a hybrid salting-out and membrane filtration process. Sep. Purif. Technol. 59, 244-252.

7. Fai, AEC; Simiqueli, APR; Andrade, CJ; Ghiselli, G; Pastore, GM. Optimized production of biosurfactant from Pseudozyma tsukubaensis using cassava wastewater and consecutive production of galactooligosaccharides: an integrated process. Biocatalysis and Agricultural Biotechnology, 2015, 4, 535-542.

8. Fan, L-L., Dong, Y-C., Fan, Y-F., Zhang, J., Chen, Q-H., 2014. Production and identification of mannosylerythritol lipid-A homologues from the ustilaginomycetous yeast Pseudozyma aphidis ZJUDM34. Carbohy. Res. 392, 1-6.

9. Faria, N.T., Santos, M.V., Fernandes, P., Fonseca, L.L., Fonseca, C., Ferreira, F.C., 2014. Production of glycolipid biosurfactants, mannosylerythritol lipids, from pentoses and d-glucose/d-xylose mixtures by Pseudozyma yeast strains. Process Biochem. 49, 1790-1799.

10. Fukuoka, T., Morita, T., Konishi, M., Imura, T., Sakai, H., Kitamoto, D., 2007a. Characterization of new glycolipid biosurfactants, tri-acylated mannosylerythritol lipids, produced by Pseudozyma yeasts. Biotechnol. Lett. 29, 1111-1118.

11. Fukuoka, T., Morita, T., Konishi, M., Imura, T., Sakai, H., Kitamoto, D., $2007 b$. Structural characterisation and surface-active properties of a new glycolipid 
biosurfactant, mono-acylated mannosylerythritol lipid, produced from glucose by Pseudozyma antarctica. Appl Microbiol Biotechnol. 76, 801-810.

12. Fukuoka, F., Morita, T., Konishi, M., Imura, T., Kitamoto, D., 2008. A basidiomycetous yeast, Pseudozyma tsukubaensis, efficiently produces a novel glycolipid biosurfactant. The identification of a new diastereomer of mannosylerythritol lipid-B. Carbohy. Res. 343, 555-560.

13. Fukuoka, T., Yanagihara, T., Imura, T., Morita, T., Sakai, H., Abe, M., Kitamoto, D., 2011. Enzymatic synthesis of a novel glycolipid biosurfactant, mannosylerythritol lipid-D and its aqueous phase behavior. Carbohy. Res. 346, 266-271.

14. Fukuoka, T., Yanagihara, T., Imura, T., Morita, T., Sakai, H., Abe, M., Kitamoto, D., 2012. The diastereomers of mannosylerythritol lipids have different interfacial properties and aqueous phase behavior, reflecting the erythritol configuration, Carbohyd. Res. 351, 81-86.

15. Hubert, J., Ple', K., Hamzaoui, M., Nuissier, G., Hadef, I., Reynaud, R., Guilleret, A., Renault, J-H., 2012. New perspectives for microbial glycolipid fractionation and purification processes. Comptes. Rendus. Chimie. 15, 18-28.

16. Isa, M.H.M., Coraglia, D.E., Frazier, R.A., Jauregi, P., 2007. Recovery and purification of surfactin from fermentation broth by a two step ultrafiltration process. J. Membrane. Sci. 296, 51-57. 
17. Isa, M.H.M., Frazier, R.A., Jauregi, P., 2008. A further study of the recovery and purification of surfactin from fermentation broth by membrane filtration. Sep. Purif. Technol. 64, 76-182.

18. Jauregi, P., Coutte, F., Catiau, L., Lecouturier, D., Jacques, P., 2013. Micelle size characterization of lipopeptides produced by B. subtilis and their recovery by the twostep ultrafiltration process. Sep. Purif. Technol. 104, 75-182.

19. Kim, H-S., Jeon, J-W., Kim, S-B., Oh, H-M., Know, T-J., Yoon, B-D., 2002. Surface and physico-chemical properties of a glycolipid bisurfactant, mannosylerythritol lipid from Candida antartica. Biotechnol. Lett. 24, 1637-1641.

20. Kitamoto, D., Akiba, S., Hioki, C., Tabuchi, T., 1990. Extracellular accumulation of mannosylerythritol lipids by a strain of Candida antarctica. Agric. Biol. Chem, 54, 3136.

21. Konishi, M., Nagahama, T., Fukuoka, T., Morita, T., Imura, T., Kitamoto, D., Hatada Y., 2011. Yeast extract stimulates production of glycolipid biosurfactants, mannosylerythritol lipids, by Pseudozyma hubeiensis SY62. J. Biosci. Bioeng. 111, $702-705$

22. Marchant, R., Banat, I.M., 2012. Biosurfactants: a sustainable replacement for chemical surfactants?. Biotechnol. Lett. 34, 1597-1605. 
23. Morita, T., Ishibashi, Y., Fukuoka, T., Imura, T., Sakai, H., Abe, M., Kitamoto, D., 2009a. Production of glycolipid biosurfactant, mannosylerythritol lipids, using sucrose by fungal and yeast strains, and their interfacial properties. Biosci. Biotech. Bioch. 73, $2352-2355$.

24. Morita, T., Ishibashi, Y., Fukuoka, T., Imura, T., Sakai, H., Abe, M., Kitamoto, D., 2009b. Production of glycolipid biosurfactant, mannosylerythritol lipids, by a smut fungus, Ustilago scitaminea. Biosci. Biotech. Bioch. 73, 788-792.

25. Morita, T., Fukuoka, T., Imura, T., Kitamoto, D., 2015a. Mannosylerythritol lipids: Production and applications. J. Oleo Sci. 64, 133-141.

26. Morita, T., Fukuoka , T., Kosaka, A., Imura, T., Sakai, H., Abe, M., Kitamoto, D., 2015b. Selective formation of mannosyl-L-arabitol lipid by Pseudozyma tsukubaensis JCM16987. Appl. Microbiol. Biotechnol. 99, 5833-5841.

27. Rangarajan, V., Dhanarajan, G., Sen, R., 2014. Improved performance of cross-flow ultrafiltration for the recovery and purification of $\mathrm{Ca}^{2+}$ conditioned lipopeptides in diafiltration mode of operation. J. Membrane. Sci. 454, 436-443.

28. Recke, V.K., Beyrle, C., Gerlitzki, M., Hausmann, R., Syldatk, C., Wray, V., Tokuda, H., Suzuki, N., Lang, S., 2013. Lipase-catalyzed acylation of microbial 
mannosylerythritol lipids (biosurfactants) and their characterization. Carbohy. Res. 373, $82-88$.

29. Saharan, B.S., Sahu, R.K., Sharma, D., 2012. A review on biosurfactants: fermentation, current developments and perspectives. Genet. Eng. Biotechnol. J. 2011, $1-14$.

30. Sajna, K.V., Sukumaran, R.K., Jayamurthy, H., Reddy, K.K., Kanjilal, S., Prasad, R.B.N., Pandeya, A., 2013. Studies on biosurfactants from Pseudozyma sp. NII 08165 and their potential application as laundry detergent additivesBiochem. Eng. J. 78, 85-92.

31. Yan, S., Liang, Y., Zhang, J., Liu, C-M., 2012. Aspergillus flavus grown in peptone as the carbon source exhibits spore density- and peptone concentration-dependent aflatoxin biosynthesis. BMC Microbiol. 12, 106-119.

32. Yu, M., Liu, Z., Zeng, G., Zhong, H., Liu, Y., Jiang, Y., Li, M., He,X., He, Y., 2015. Characteristics of mannosylerythritol lipids and their environmental potential. Carbohy. Res. 407, 63-72. 